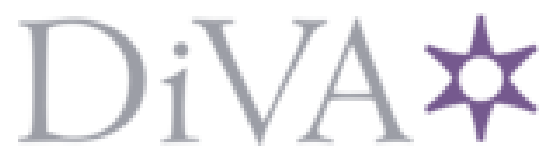

http://www.diva-portal.org

This is the published version of a paper published in ZDM - the International Journal on Mathematics Education.

Citation for the original published paper (version of record):

Kullberg, A., Runesson, U., Marton, F. (2017)

What is made possible to learn when using the variation theory of learning in teaching mathematics?.

ZDM - the International Journal on Mathematics Education, 49(4): 559-569

https://doi.org/10.1007/s11858-017-0858-4

Access to the published version may require subscription.

N.B. When citing this work, cite the original published paper.

Open Access

Permanent link to this version:

http://urn.kb.se/resolve?urn=urn:nbn:se:hj:diva-35499 


\title{
What is made possible to learn when using the variation theory of learning in teaching mathematics?
}

\author{
Angelika Kullberg $^{1} \cdot$ Ulla Runesson Kempe $^{2,3} \cdot$ Ference Marton $^{1}$
}

Accepted: 21 March 2017 / Published online: 7 April 2017

(c) The Author(s) 2017. This article is an open access publication

\begin{abstract}
The variation theory of learning emphasizes variation as a necessary condition for learners to be able to discern new aspects of an object of learning. In a substantial number of studies, the theory has been used to analyze teaching and students' learning in classrooms. In mathematics education, variation theory has also been used to explore variation in sets of instructional examples. For example, it has been reported how teachers, by using variation and invariance within and between examples, can help learners to engage with mathematical structure. In this paper, we describe the variation theory of learning, its underlying principles, and how it might be appropriated by teachers. We illustrate this by an analysis of one teacher's teaching before and after he participated in three lesson studies based on variation theory. Both the theory and the empirical illustration focus on "what is made possible to learn' in different learning situations. We show that in the two analyzed lessons, different things were made possible to learn.
\end{abstract}

Keywords Variation theory $\cdot$ Teaching $\cdot$ Mathematics . Algebra $\cdot$ Learning study $\cdot$ Lesson study $\cdot$ Teacher collaboration

Angelika Kullberg

Angelika.Kullberg@gu.se

1 Department of Pedagogical, Curricular and Professional Studies, University of Gothenburg, Box 300, 40530 Gothenburg, Sweden

2 School of Education and Communication, University of Jönköping, 55318 Jönköping, Sweden

3 Wits School of Education, University of the Witwatersrand, Johannesburg, South Africa

\section{Introduction}

The variation theory of learning (Marton 2015; Marton and Booth 1997) points to variation as a necessary component in teaching in order for students to notice what is to be learned. Studies on how variation can be used to enhance students' learning have been reported (e.g., Bartolini Bussi et al. 2013; Huang and Yeping 2017; Marton 2015; Marton and Pang 2013; Sun 2011; Watson and Mason 2006). A conclusion drawn from these studies is that how the content is handled and what aspects are made possible to discern in a lesson affects what is made possible to learn. Analysis of 'what is made possible to learn' from a lesson, we believe, also says something about 'what is not made possible to learn'. What is and what is not made possible to learn, seen from a variation theory perspective, is often analyzed from classroom data in which the interaction between the teacher and the students in regard to the content taught is in focus. However, in the empirical illustration presented in this paper, we analyze the examples used by the teacher without taking into account the interaction, which we usually analyze (e.g., Kullberg and Runesson 2013). The data presented come from a larger study about mathematics and science teachers' teaching after they are engaged in a theory-driven lesson study intervention of 1.5 years, in which they used variation theory. One finding is that teachers, after participating in this particular professional development, make other aspects of the content noticeable for the students through their teaching (Kullberg et al. 2016; Nilsson 2014; Vikstrom 2014). The aim of this paper is to demonstrate how a lesson design can be analyzed from the point of view of the theory. 


\section{Variation theory as an instructional design principle}

The point of departure of variation theory concerns the means with which we can help learners to handle novel situations in powerful ways (Marton and Pang 2006). Originating from the phenomenography tradition, variation theory posits that learning implies seeing or experiencing critical aspects of an object of learning (Marton and Booth 1997; Marton 2015). The object of learning provides answers to the question 'What is to be learned?' in three ways: it defines (1) the content, (2) the educational objective, and (3) what needs to be learned (critical aspects). The object of learning may be different for different learners.

Learning, from a variation theory point of view, implies differentiation rather than accumulation (cf., Gibson and Gibson 1955). Thus, variation theory spells out the conditions of learning and explains learning failures in a specific way: when learners do not learn what was intended, they have not discerned the necessary aspects. So, the very core idea of variation theory is that discernment is a necessary condition of learning: what aspects we attend to or discern are of decisive significance for how we understand or experience the object of learning. Discernment cannot happen without the learner having experienced variation, however. To discern and focus on aspects (or dimensions of variation), the learner must have experienced variation in those aspects. For instance, it is more likely that learners in a physics lesson (new situation) will identify that the letters in Ohm's law $U=R \times I$ represent variables if they have experienced algebraic expressions with letters other than just $x$ representing variables in mathematics. If they have experienced equations with letters other than just $x$, it is more likely that they will discern that the letter may be arbitrarily chosen (cf., Häggström 2008). So, to make the (critical) aspect possible to discern, the teacher must open up the aspect as a dimension of variation ( $x$ could be replaced by other letters/symbols). Mason and Watson (2006) and Mason (2017) argue in a similar way: variation can structure sense-making by drawing attention to the targeted aspects when teaching mathematics.

One of the most specific tenets of variation theory is that seeing differences precedes seeing sameness (Marton and Pang 2006, 2013). Marton and Pang (2013) state that when helping learners to make a novel meaning their own, such as when helping students to understand a new concept, we frequently point to examples that share the aimed-at meaning but differ otherwise, for example, pointing to examples of linear equations and declaring, "This is a linear equation and this is a linear equation". Marton and Pang (2013) argue against this view of developing new meanings from the experience of sameness, as variation theory claims the opposite:
You cannot possibly understand what Chinese is simply by listening to different people speaking Chinese if you have never heard another language, and you cannot possibly understand what virtue is by inspecting different examples of the same degree of virtue. Nor can you understand what a linear equation is by looking only at linear equations. (p. 25)

From a pedagogical/instructional point of view, following this principle of the experience of difference before sameness has certain implications. For instance, to understand the concept of a linear function $y=m x+b$ one needs to know how it differs from non-linear functions. Otherwise it is merely a synonym for 'function'. Similarly, a triangle must be compared to a circle or any other shape to have a meaning of its own. In variation theory, comparing two concepts involves a particular pattern of variation called 'contrast'. One could argue that this is similar to counter examples, which are often used in mathematics to justify conjectures and generalizations.

In lesson designs premised on variation theory, contrast (which could be a counter example) is used with a specific aim: to help learners acquire novel meanings by opening up appropriate dimensions of variation (see Marton and Pang 2013; Marton 2015). Contrast has to be followed by generalization. To generalize the idea of a function, for instance, one must experience sameness, certain defining aspects, of different functions. Thus, in order to see not just one instance of function as a function, you must see the same set of aspects within different functions and the part-whole relation between those aspects, as a commonality across various instances you encounter. In this way, defining aspects are separated from the particular instance and a generalization can be made. As far as this pattern of variation is concerned, the targeted aspect is kept invariant while other aspects vary. So, for instance, if the aspect 'slope' is opened up as a dimension of variation, it is made possible to experience that a linear function could have different slopes by varying the m-value (different positive/negative values) and keeping the b-value invariant. However, understanding the object of learning implies understanding the object as a whole and thus involves a simultaneous discernment of the defining aspects and their relationship. When dimensions of variation corresponding to several critical aspects are opened up simultaneously, fusion can take place. Marton (2015) suggests a prototype for how to sequence patterns of variation and invariance to bring about learning, as follows: starting with the undivided object of learning, usually a problem to solve aiming at getting the learners acquainted with the situation or what is to be mastered, followed by contrast, generalization and finally fusion (p. 263). 
So, what this boils down to is a conjecture suggesting that patterns of variation and invariance and how these are sequenced, which are inherent in tasks, examples, illustrations and interactions between teachers and learners, are of decisive importance for what is made possible to learn. When these principles are used for instructional design, many of the ideas about teaching which are taken for granted by teachers are challenged, such as, for instance "teaching one thing at a time" (Zhang 2009), "never making use of incorrect answers to make a contrast" (Ekdahl and Runesson 2015) or "always starting with sameness instead of differences" (Marton and Pang 2013). When guided by variation theory in planning for learning, the teacher must become aware of not just what the critical aspects might be, but how to open them up as dimensions of variation and to determine what values in those dimensions would be critical. However, in addition to affording patterns of variation in sets of examples, it is also important that teaching draws attention to those patterns (Kullberg et al. 2014). Students can also open up dimensions of variation when working individually (Runesson 2006), or in group or whole-class discussions (Kullberg 2012).

When analyzing how the object of learning is handled during teaching, the 'intended', the 'enacted', and the 'lived' objects of learning are used to differentiate between the teacher's particular goal and intention regarding what the students should learn (intended object of learning), what is made possible to learn in the lesson (the enacted object of learning), and what the learners actually learn (lived object of learning). Even if the teacher plans to enact an object of learning in a certain way, this may be different from what is actually made possible for the learners to discern in the classroom.

\section{Variation and exemplification}

The benefits of using multiple examples rather than only one example in mathematics education, in regard to student learning, have been argued by several scholars (e.g., Dienes 1960; Gentner 2005; Rittle-Johnson and Star 2009; Schwartz and Bransford 1998). It has been found that two examples are better than one, and that two examples presented together are better than two examples presented separately (Rittle-Johnson and Star 2009, p. 529). The variability of the examples compared is of importance in order for multiple examples to be effective (Rittle-Johnson and Star 2009). An important question to consider in relation to these findings is "When two examples are to be compared, what dimensions of the examples should vary and what dimensions should remain the same?" (ibid., p. 530). It has been shown that the use of mixed examples (examples of different types) facilitates student learning more than the use of multiple examples of the same type (Hatala et al. 2003; Kornell and Bjork 2008; Rohrer and Pashler 2010; Schmidt and Bjork 1992; Taylor and Rohrer 2010). When different types of tasks or examples are mixed, the learners are forced to distinguish between them and thus get better at making sense of novel tasks and examples. Other studies have shown that students' prior knowledge affects learning when comparing multiple examples (Rittle-Johnson et al. 2009), and when a mix of correct and incorrect examples is used in worked examples (Große and Renkl 2007). It has been argued that differences in the examples used that are too difficult to align can be less beneficial for student learning (Gentner and Markman 1994).

Watson and Mason (2006) argue that a mathematical exercise, e.g., a collection of questions or tasks, is to be seen as one single (mathematical) object, as follows: the task as a whole (or collection of questions), which is focused on by the students and the teacher during a lesson, and upon which the learner acts intelligently and mathematically, by observing, analyzing, exploring, questioning, transforming, etc. Watson and Mason suggest that it is the structure of the exercise as a whole, not the individual items, that promotes common mathematical sense-making (p. 97). They argue that "tasks that carefully display constrained variation are generally likely to result in progress in ways that unstructured sets do not" (p. 92), and that wisely planned variation, for instance in a task or set of examples, can make certain aspects noticeable for the learner. "Constructing tasks that use variation and change optimally is a design project in which reflection about learner response leads to further refinement and precision of example choice and sequence" (p. 100). Watson and Mason (2006, p. 109) suggest that carefully designed sequences of examples with systematic variation can make it possible for students to discern similarities and differences. The use of systematic variation in examples for mathematics teaching in regard to students' learning has been studied within a variation-theory framework (e.g., Al-Murani 2007; Goldenberg and Mason 2008; Gu et al. 2004; Guo et al. 2012; Huang et al. 2016; Pillay 2013; Rowland 2008; Watson and Chick 2011). Findings from these studies indicate that variation theory as a design principle can make certain aspects of the content noticeable for the learner and thereby enhance learning. For example, we see this result in Pillay's (2013) study of teachers who used variation theory in a theory-driven lesson study (learning study) about functions in Grade 10. In an iterative process, the teachers planned, analyzed, and revised one single lesson about linear and exponential functions three times. The team found that when examples of different types of functions (linear and exponential) were presented and classified one at a time in a lesson, this had less effect on student learning than when different types of functions were discussed simultaneously (linear and exponential 
functions). A conclusion was that taking two types of functions at the same time seems to provide enhanced opportunities for noticing and distinguishing critical aspects of the types of functions, compared to when they were discussed one function at a time.

Rowland (2008) argues that "examples provided by a teacher ought, ideally, to be the outcome of a reflective process of choice, a deliberate and informed selection from available options, some 'better' than others" (p. 151). However, studies indicate that examples used in teaching may not be planned in great detail nor are they the subject of deeper reflection. A study of prospective elementary school teachers' examples showed that the choice of examples was randomly made (Rowland 2008; Rowland et al. 2003). Rowland (2008) found that examples used in some cases did not provide the opportunity for the students to distinguish between aspects of what was taught. For instance, when $(1,1)$ was used by one prospective teacher as coordinates in a Cartesian coordinate grid, it was not possible to distinguish between the $\mathrm{x}$ - and $\mathrm{y}$-values. Other coordinates, e.g., $(1,2)$ followed by $(2,1)$ would have provided a better opportunity to discern differences between the axes. From the theoretical standpoint taken, we argue that which examples are chosen and how they are enacted together with students, are of decisive importance. Zodik and Zaslavsky's (2008) study indicates that teachers' choices of examples are seldom discussed. In a study of five in-service teachers' choices of examples, it was found that the teachers had never talked about their use of examples in pre-service training or with other colleagues in the school (Zodik and Zaslavsky 2008). In the following section, we give an empirical illustration of one teacher's teaching after he had worked with variation theory as a design principle for teaching. We use the Goldenberg and Mason (2008) notion of instructional example space to describe the examples teachers use, e.g., in a task. Goldenberg and Mason argue that teachers' example construction, pre-planned or done by the teacher in the heat of the moment, "reveals a good deal about the teacher's accessible example space in that situation, and hence the scope of their awareness and the focus of their attention" (p. 189). The examples used say something about what the teacher knows and wants her students to notice and pay attention to. We analyse one teacher's instructional example space in order to see what patterns of variation the teacher enacted, and what was made possible to learn in lessons about the same topic on two different occasions.

\section{Teaching with variation}

In this section, we report on empirical data from a research project about mathematics and science teaching in which teachers used variation theory as a design principle (Kullberg 2016; Kullberg et al. 2016; Runesson and Kullberg 2017). We analyzed lessons taught in Grade 7 (13-year-old students) before and after teachers had been engaged in learning studies. In a learning study (Cheng and Lo 2013; Marton 2015; Marton and Pang 2006; Lo 2012), a team of teachers systematically plan, enact, analyze and revise a lesson in order to help the students to learn the intended object of learning. One significant difference between a lesson study (Lewis et al. 2009; Yoshida 1999) and a learning study is that the teachers use variation theory (or another theory) as a tool to plan and analyze lessons. For 1.5 years, a total of twelve secondary-school teachers in four teams worked together with one researcher per team. The teachers were subject experts certified to teach mathematics in lower secondary schools. The schools were public schools with heterogeneous classes. Although the majority of the students had Swedish as their first language, there were students with other ethnic and linguistic backgrounds in all classes. The schools were located in suburban areas of larger cities in four different parts of Sweden. Each team conducted three learning studies, one each semester, on different topics in mathematics or natural science. For each learning study, the teachers met for about seven meetings in which they pre-planned the study, designed pre- and posttests, planned and revised three lessons and finally summarized their findings. In each study, one lesson was carefully planned, implemented in one class by one of the teachers in the team, analyzed and revised collaboratively, and enacted in another class (second lesson) by another teacher. The second lesson in the iterative cycle was analyzed and revised, and finally a third lesson was planned and enacted in a third class. In the process, the teachers identified critical aspects for students' learning of the object of learning. The team planned the lessons collaboratively and collected information from pre- and post-tests to analyze how the teaching affected their students' learning (cf., Guskey 2002). They used ideas from variation theory to design the lessons; for instance, they were aware of some patterns of variation, e.g., contrast and generalization, and the idea of identifying critical aspects for students' learning. Our research interest in this study was to explore whether and in what way the intervention affected the teachers' individually planned teaching. We assumed that it is possible to study aspects of what teachers learned from participating in the theory-driven professional learning community via analysis of their teaching as "knowing-in-action" (Schön 1983) or knowing as a disposition to act (Ryle 1949/2002). To explore changes in teaching practice, classroom data from before and after the learning study intervention was collected and analyzed. One individually planned and enacted lesson (Lesson 1) on a topic of the teacher's choice before the intervention, and one lesson (Lesson 2) on the 
same topic two years later, were video recorded. We identified similar differences in ten of the twelve teachers' teaching after the intervention, in terms of how the content was handled during the lessons (Kullberg et al. 2016). Two of the twelve teachers were excluded from the analysis, one because she changed the topic taught in the two lessons, and the other because he taught the two lessons by following a textbook when doing laboratory work. Although in the ten analyzed cases, the teachers taught different topics, they taught concepts in relation to other relevant concepts in Lesson 2, whereas in Lesson 1, one concept was taught at a time. We further studied the examples used before and after the intervention on a micro-level. In this paper, we give an empirical illustration and analysis of one teacher's teaching of a method for solving equations with one unknown.

\subsection{Differences in what was made possible to discern}

There were general similarities between Lesson 1 (L1) and Lesson 2 (L2). For instance, the lessons were about the same length and the same method (cancellation) for solving equations with one unknown was taught. In both lessons, the students worked with creating equations with one unknown for a fellow student. We focused on similarities and differences in enacted example spaces in order to explore, on a micro-level, effects of the intervention on teaching practice. We analyzed the examples introduced by the teacher during whole-class discussion using a variationtheory framework (Marton 2015). Our analysis shows that the enacted object of learning, and thereby what was made possible to learn in the lesson, had changed. In L1, the object of learning entailed primarily the method and procedure for solving, by finding answers to equations with one unknown. When the same teacher taught L2 on the same topic after the intervention, the answers to the equations used in the lesson were already known, and the object of learning was instead about understanding the structure of an equation: how an equation can be created and the operations used in solving it.

The teacher also articulated these differences between the lessons. With regard to the intended object of learning in L1, he said that he wanted the students to be "more secure in the method (cancellation), ..., but it is more than the method I am after, ..., they should see that it is possible to solve an equation, see the use of it, that it is a good way, that it falls into place so to say." After the intervention, he said about L2: "My point is that if you understand what an equation is and how it is structured then you are able to solve them ... you can teach them a method to solve the equation without them really understanding what an equation is, because you teach them a method that gives a result, but the question is if they have foundational understanding of what an equation is". We suggest that the teacher, in this case, has changed the intended and enacted objects of learning, and his view on what students need to learn in order to be able to solve equations with one unknown. In the following analysis, we show how the tasks and examples used made it possible for the students to discern different aspects (dimensions of variation).

\subsection{Lesson 1}

Our analysis of Lesson 1 suggests that the enacted object of learning and what dimensions of variation were opened up primarily brought out the process of solving equations with one unknown. The teacher, together with the students, solved one numerical equation with iconic representation (Task 2) and two equations made from word problems (Task 4), using the method of cancellation. In the following section, the tasks and which aspects are varied/invariant in the enacted sets of examples are analyzed.

\subsubsection{Solving equations with different numbers}

In Task 1 (see below), several examples of equations with different numbers on each side of the equal sign were solved and discussed, one after the other, in order to illustrate equality. In the two first examples, 12 is invariant, but the side on which twelve is placed is varied as well as the factors that multiply to give 12 . Hence, in the first three examples of equations, the teacher varied the numbers, the order of numbers, and the number of factors on each side of the equal sign, while keeping the equality/equal sign invariant.

1. $3 \times 4=12$

2. $12=3 \times 2 \times 2$

3. $12 \times 2=3 \times 2 \times 2 \times 2$

4. $3 \times 6=18 \times 2=363 \times 6 \neq 18 \times 2=36$

This was followed by one example (see example no. 4) in which the teacher made a contrast between an incorrect $(3 \times 6=18 \times 2=36$, 'to show steps in a calculation process'), ${ }^{1}$ and a correct way $(3 \times 6 \neq 18 \times 2=36)$ of using the equal sign. In this case, the meaning of the equal sign varied, compared to the previous equations, and a new sign representing inequality was introduced. It was made possible to discern that, although represented differently, all parts of the equation must have the same value in order for the equal sign to be used correctly.

\footnotetext{
1 This incorrect way of using the equal sign 'to show steps in a calculation process' is commonly used by Swedish students in this grade.
} 
Fig. 1 Variation in representation (numerical and iconic) of the solving process of the same equation (Task 2). Note: five stones on both sides of the scale have been erased as the first step in the solving process

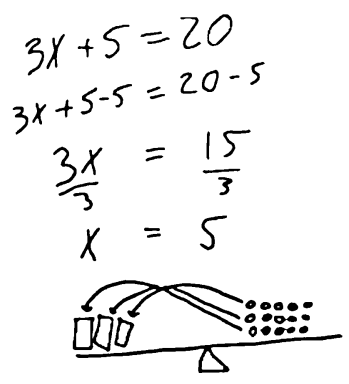

to the context (price, age), the operations used in the equations (addition, division) and the numbers in the equations. The same method (invariant) was used to solve them. Hence, it was made possible to discern that equations with one unknown can represent different situations and solve different problems.

\subsection{Lesson 2}

Our analysis of Lesson 2 suggests that the enacted object of learning emphasized understanding equations, their structure and how different operations (addition, subtraction, multiplication and division) affect an equation. (In Lesson 1 , operations were used when solving equations with one unknown without attention being drawn to this aspect.) The answers to the three equations presented during the lesson were already known from the start. In Task 5, the teacher used the same equation $(3+4=7)$ to create three different equations with one unknown (Fig. 2). First, by substituting 3 with $x$ the equation $x+4=7$ was created. In the second equation, $x$ is varied when 4 (in $3+4=7$ ) was substituted with $2 \times(3+2 x=7)$. In the third equation $3+4=7$ remains the starting point from which $x$ is varied again, when 3 is substituted (with $6 x \div 4$ ) in the equation $6 x \div 4+4=7$. It was made possible for students to see the creation of an equation with unknown numbers and the solving process for that equation simultaneously. Therefore in Lesson 2, the focus of attention was not primarily on finding the answer, but instead on understanding what an equation is, by varying $x$ and the operations used in the solving process. In the following section, we illustrate our analysis, starting with Task 1.

\subsubsection{Equality represented by different operations}

Task 1 brought out, in a similar way to L1, the meaning of the equal sign/equality by varying equality and inequality. However, in L2, more sets of examples illustrate this, and the numbers used in one set of examples remained invariant (e.g. $6 \times 4$ ), varying different operations and equations. In L2, the first two examples illustrated inequality, compared to L1 in which equality was the starting point. So, in L 2 the starting point was a contrast between an incorrect ('to show steps in a calculation process') and a correct way to use the equal sign.

1. $12 \times 4 \neq 48 \div 2=24$

2. $6 \times 4 \neq 24 \div 2=12$

3. $6 \times 4=48 \div 2=24$

4. $6 \times 4=12 \times 2=24$

5. $6+2=8$

6. $6+2 \neq 8 \div 2=4$ 
Fig. 2 The same equation is used to create and solve three different equations with one unknown in L2: illustration of the white board (Task 5)

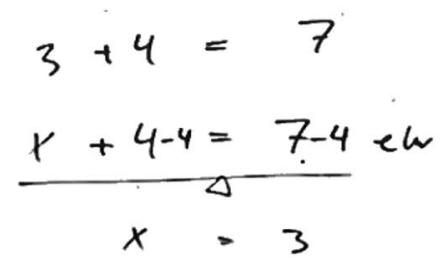

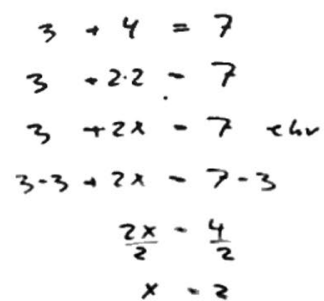

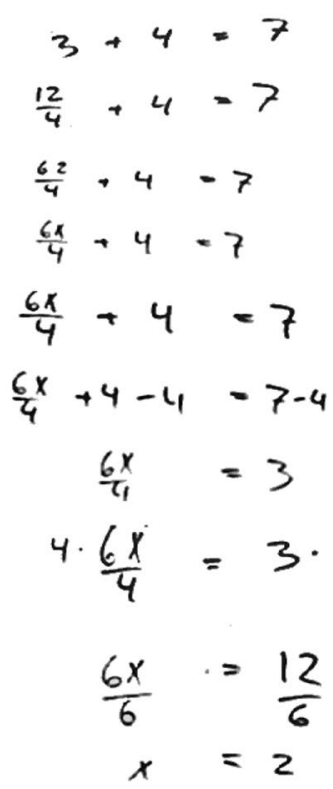

It was made possible to discern that, although represented differently, all parts of the equation must have the same value in order for the equal sign to be used correctly. Hence similar dimensions of variation were opened in L2 (Task 1) and in L1 (Task 1).

\subsubsection{Equality represented by different operations}

Task 2 was about addition and multiplication and focused on representation and the difference between multiplication with integers and multiplication with $x$. Two examples, one with integers and one with $x$ were contrasted to show how $3+3+3+3=4 \times 3$ is not 43 , whereas $x+x+x+x=4 \times x$ is the same as $4 x$. Hence the representation of the same number value varied, keeping the multiplier (4) and $x$ invariant. It was made possible to discern that when representing the multiplicand with $x$, the multiplication sign can be omitted. Moreover, it was possible to discern that a known number could be replaced by $x$.

\subsubsection{Equality handled by different operations}

How operations change or maintain the equality in an equation became a highlighted theme in Tasks 3 and 4 and this, we would suggest, was accomplished by systematic variation between examples. In Task 3 (see below), four examples show how multiplication and division with the same number affects the equation.

1. $5 \times 3 \div 5=15 \div 5=3$

2. $\mathbf{5} \times \mathbf{3} \div 3=15 \div 3=\mathbf{5}$

3. $6 \times 4 \div 6=4$

4. $6 x \div 6=x$
In the first two examples, $5 \times 3 \div 5=15 \div 5=3$ and $5 \times 3 \div 3=15 \div 3=5$, the factors ( 5 and 3 ) remain invariant, with only the divisor varying. In the first example, 5 divided the factors, whereas in the second example 3 divided them. This was further explored when one student asked for another example to verify the teacher's statement "If you have a number (5) and you multiply that number by another number $(\times 3)$ and then divide by one of the numbers (e.g., $\div 5$ ) you will get the other number back (3)". So, when a new example, this time with quite different numbers, $6 \times 4 \div 6=4$, was given, again it was made possible to experience multiplication and division with the same number (factor/divisor). The last equation $6 x \div 6=x$ is similar to $6 \times 4 \div 6=4$; in this case 4 is used instead of $x$ in the equation. From the examples enacted, it was made possible to discern that multiplying and dividing by the same number does not change the value. In the same way as in Task 2, it was made possible to discern that a known number could be replaced by $x$.

\subsubsection{Properties of equality}

How to operate on an equation/equality was further discussed in Task 4 (see below). However, in Task 4, this involved addition, subtraction and multiplication. The equation $3+4=7$ remained invariant through the five examples, whereas the operations varied between them.

1. $3+4=7$

2. $2+3+4=7+2$

3. $2+3+4-5=7+2-5$

4. $2 \times 3+4 \neq 7 \times 2$

5. $2 \times 3+4 \times 2=7 \times 2$ 
It was demonstrated that equality can be maintained although the equation is operated on, drawing attention to the additive property of equality $(a+c=b+c)$, the multiplication property of equality $(\mathrm{a} \times \mathrm{c}=\mathrm{b} \times \mathrm{c})$, and the distributive property $\mathrm{a} \times(\mathrm{b}+\mathrm{c})=(\mathrm{a} \times \mathrm{b})+(\mathrm{a} \times \mathrm{c})$. Operations with addition and subtraction were compared to operations with multiplication. When changing from the example $2+3+4-5=7+2-5$, to multiplying $3+4=7$ by 2 into $2 \times 3+4 \neq 7 \times 2$, it was made possible to notice the distributive property $(2 \times 3)+(4 \times 2)=7 \times 2$. Hence, it was made possible to discern that the same operation needs to be carried out on both sides of the equal sign in order to maintain the equality, and that in multiplication both addends on each side need to be operated on. We can see that the changes between the examples are few and systematic.

\subsubsection{Creating and solving equations}

In Task 5 , one equation, $3+4=7$, was used to create and solve three different equations (see Fig. 2, and below) with one unknown. As has previously been argued, the three equations made it possible for students to focus on the structure of the equation and the process for solving it rather than on finding an answer.
1. $x+4=7$
2. $3+2 x=7$
3. $6 x \div 4+4=7$

The value that $x$ could have varied, whereas the other parts of the equation and the method of solving were invariant. It was made possible to discern how different equations with one unknown can be made from the same equation.

\subsection{Different learning possibilities}

Even though the teacher taught the same topic in both lessons, we suggest that L1 and L2 made different dimensions of variation (aspects) possible to discern, and therefore made it possible to learn different things. In L1, the dimensions of variation concerned mainly: (1) the meaning of the equal sign/equality $(=, \neq),(2)$ representation (iconic, symbolic), (3) non-solvable equations (solvable, non-solvable), (4) context (stones, price, age), in regard to solving equations with one unknown. In L2, the dimensions of variation instead concerned: $(1)$ the equal sign/equality $(=, \neq)$, (2) representation of an equation/an unknown (multiplication by an integer, multiplication by $x$ ), (3) operating on the equality (multiplication, division), (5) properties of equality (additive, multiplication), and (5) how equations can be made (what $x$ represents varied). The dimensions of variation opened up, in L1 and L2 respectively, made it possible for the students to experience two quite diverse objects of learning. In L1, the object of learning was primarily the method and procedure for solving, whereas in L2 it was instead about understanding the structure of equations. The teacher's articulation of what he wanted the learners to learn supports our analysis that there were two different objects of learning.

The analysis shows that in L1 and L2, the unknown $x$ is handled in different ways. In L1, the unknown number in the equation is the starting point and thus, the $x$-value is to be calculated. In L2, it is the other way around. In Task 2 , a known number (3) is replaced by $x$. In the same way, in Task 3 , the number 4 in $6 \times 4 \div 6=4$ is substituted with $x$ to give $6 x \div 6=x$. In Task 5 , the teacher created three equations with one unknown based on the equation $3+4=7$. We suggest that knowing the value of $x$ in Task 5 from the start, and not having to calculate $x$, made it possible to focus on the structure of the equations in L2 and not primarily on the answers.

However, we want to remark that we cannot draw conclusions about whether the dimensions of variation (aspects) enacted in the lessons were actually critical for students' learning. This has not been studied and is not within the scope of this paper. There might be other aspects that these students need to discern in order to learn the required ability. We can only conclude that the two lessons offered two quite different possibilities for learning, since different dimensions of variation were opened up and thus were made possible to experience.

\section{Concluding remarks}

As the variation theory of learning has the aim of revealing the necessary conditions for learning in specific cases, it also can be used to envisage what it is possible to learn with one lesson design or with another, and in consequence if you can make a statement about what it is possible to learn, then you may even understand why students fail to learn. In this paper we have analyzed what is made possible to learn in two lessons. We find it necessary to make a distinction between learning that happens through teaching, on the one hand, and learning made possible through teaching, on the other hand. This distinction is useful if you want to, for example, develop a lesson design, or analyze lessons as in the empirical illustration in this paper. The analysis of what is made possible to learn also sheds light on what is not made possible to learn. For instance, from a variation theory perspective, it was not made possible to discern the distributive property in L1 since this was not brought up as a dimension of variation, whereas in L2 it was made possible to experience this through contrast (difference) between $2 \times 3+4 \neq 7 \times 2$ and $(2 \times 3)+(4 \times 2)=7 \times 2$. Marton (2015) suggests, "A necessary condition for finding 
and experiencing a certain aspect of an object of learning is that the learner has the opportunity to encounter differences in the relevant dimension of variation" (p. 128). The learner herself, a teacher, other students, a task, or a set of examples could make it possible for the learner to experience differences (as well as similarities) in relation to critical aspects. Well-designed tasks and examples, however, are usually insufficient for learning. In addition to example sequences that incorporate certain patterns of variation (differences) and invariance (similarities), it is important that teaching draws attention to those patterns (Kullberg et al. 2014). We want to acknowledge, however, that there is not a one-to-one-correspondence between teaching and learning. Even if it is made possible to learn certain things in a lesson, students may not learn. Their attention may not be attuned to the dimensions opened; it may be directed at other things going on in the classroom or in the students' minds, for instance.

The empirical illustration in this paper, about analysis of teachers' use of examples only, is non-typical for this research tradition. With regard to the empirical illustration, we do not suggest that lessons can be reduced to the examples chosen by the teacher. Analysis of tasks and examples can say something about what is made possible to discern and about necessary conditions for learning, but is, however, not sufficient in itself. Most often studies using this framework also analyze teaching, students' contributions during lessons, and students' learning, as a whole. Nevertheless, the empirical illustration sheds light on an important distinction that we find useful when it comes to analyzing teaching and learning in classroom settings.

\subsection{Future research}

We advocate that analyzing what is made possible to learn can also say something about what is not made possible to learn. This in turn can say something about why students in school are not learning what the teacher intends them to learn. We suggest that what the critical aspects are for different groups of learners and for different objects of learning needs to be further explored. It is, however, not beneficial for learning to only tell students about the identified critical aspects, since these aspects need to be experienced (Kullberg 2010; Marton and Tsui 2004). Therefore, future research needs to take into account both what aspects are made possible to discern in a lesson, as well as how they are enacted in the interaction with the students.

\subsection{Recommendations for mathematics educators}

It cannot be derived from the variation theory of learning how specific content should be handled in the classroom, what the critical aspects are, or what examples to use when teaching. It is the teachers who have to decide what needs to come to the fore of students' attention, what the critical aspects might be and how these can become visible for learners.

The theory can, however, serve as a tool for teachers when they plan and enact teaching. The theory offers tools that teachers can use to focus on the mathematical content taught, students' understanding of it and how to enable possibilities for learning. Theoretical concepts like the object of learning and its critical aspects can help educators to focus on the ability to be learned, and on what students need to learn in order to do so. Another important idea within the theory is how we can help learners to notice what we want them to discern. If an aspect that we want our students to notice is varied against an invariant background, it is more likely that students will discern it (Marton and Pang 2013). As stated previously, variation and invariance in teaching does not guarantee learning; it can, at best, make it possible for learning to happen.

Acknowledgements This work was supported by the Swedish National Research Council [Grant Number 2009-4686].

Open Access This article is distributed under the terms of the Creative Commons Attribution 4.0 International License (http:// creativecommons.org/licenses/by/4.0/), which permits unrestricted use, distribution, and reproduction in any medium, provided you give appropriate credit to the original author(s) and the source, provide a link to the Creative Commons license, and indicate if changes were made.

\section{References}

Al-Murani, T. (2007). The deliberate use of variation to teach algebra: a realistic variation study. (Doctoral thesis). Oxford: University of Oxford.

Bartolini Bussi, M. G., Sun, X., \& Ramploud, A. (2013). A dialogue between cultures about task design for primary school. In C. Margolinas (Ed.), Proceedings of ICMI Study 22: Task Design in Mathematics Education. Oxford: ICMI.

Cheng, E. C., \& Lo, M. L. (2013). "Learning study": Its origins, operationalisation, and implications". OECD Education working papers. doi:10.1787/5k3wjp0s959p-en.

Dienes, Z. (1960). Building up mathematics. London: Hutchinson Educational.

Ekdahl, A.-L., \& Runesson, U. (2015). Teachers' responses to incorrect answers on missing number problems in South Africa. In X. Sun, B. Kabur, \& J. Novotná (Eds.), The twenty-third ICMI Study: Primary Mathematics Study on Whole Numbers. Macau, China, June 3-7.

Gentner, D. (2005). The development of relational category knowledge. In D. H. Rakison \& L. Gershkoff-Stowe (Eds.), Building object categories in developmental time (pp. 245-275). Mahwah, NH: Erlbaum.

Gentner, D., \& Markman, A. B. (1994). Structural alignment in comparison: No difference without similarity. Psychological science, 5(3), 152-158.

Gibson, J. J., \& Gibson, E. J. (1955). Perceptual learning: Differentiation-or enrichment? Psychological Review, 62(1), 32-41. 
Goldenberg, P., \& Mason, J. (2008). Shedding light on and with examples spaces. Educational Studies in Mathematics, 69(2), 183-194.

Große, C. S., \& Renkl, A. (2007). Finding and fixing errors in worked examples: Can this foster learning outcomes? Learning and Instruction, 17(6), 612-634.

Gu, L., Huang, R., \& Marton, F. (2004). Teaching with variation: A Chinese way of promoting effective mathematics learning. In L. Fan, N.-Y. Wong, J. Cai \& S. Li (Eds.), How Chinese learn mathematics. Perspectives from insiders. Singapore: World Scientific.

Guo, J.-P., Pang, M. F., Yang, L.-Y., \& Ding, Y. (2012). Learning from comparing multiple examples: On the dilemma of "similar" or "different". Educational Psychology Review, 24(2), 251-269.

Guskey, T. R. (2002). Professional development and teacher change. Teachers and teaching. Theory and Practice, 8(3), 381-391.

Häggström, J. (2008). Teaching systems of linear equations in Sweden and China: What is made possible to learn? Göteborg Acta Universitatis Gothoburgensis.

Hatala, R. M., Brooks, L. R., \& Norman, G. R. (2003). Practice makes perfect: The critical role of mixed practice in aquisition of ECG interpretation skills. Advances in Health Sciences Education, 8(1), 17-26.

Huang, R., Gong, Z., \& Han, X. (2016). Implementing mathematics teaching that promotes students' understanding through theorydriven lesson study. ZDM, 48(4), 425-439.

Huang, R., \& Yeping, L. (Eds.). (2017). Teaching and learning mathematics through variation. Confusian heritage meets western theories. Boston, MA: Sense.

Kornell, N., \& Bjork, R. A. (2008). Learning concepts and categories. Psychological Science, 19(6), 585-592.

Kullberg, A. (2010). What is taught and what is learned. Professional insights gained and shared by teachers of mathematics. Göteborg: Acta Universitatis Gothoburgensis.

Kullberg, A. (2012). Students' open dimensions of variation. International Journal for Lesson and Learning Studies, 1(2), 168-181.

Kullberg, A. (2016). Variation within sets of examples. Paper presented at the 13th International Congress on Mathematical Education, ICME. Hamburg, 24-31 July.

Kullberg, A., \& Runesson, U. (2013). Learning about the numerator and denominator in teacher-designed lessons. Mathematics Education Research Journal, 25(4), 547-567.

Kullberg, A., Runesson, U., \& Mårtensson, P. (2014). Different possibilities to learn from the same task. PNA, 8(4), 139-150.

Kullberg, A., Runesson, U., Marton, F., Vikstrom, A., Nilsson, P., Martensson, P., \& Haggstrom, J. (2016). Teaching one thing at a time or several things together?-Teachers changing their way of handling the object of learning by being engaged in theory-based professional learning community in Mathematics and Science. Teachers and teaching. Theory and Practice, 22(6), 1-15.

Lewis, C., Perry, R., \& Hurd, J. (2009). Improving mathematics instruction through lesson study: A theoretical model and North American case. Journal of Mathematics Teacher Education, 12(4), 285-304.

Lo, M. L. (2012). Variation theory and the improvement of teaching. Gothenburg, Sweden: Acta Universitatis Gothoburgensis.

Marton, F. (2015). Necessary conditions of learning. New York: Routledge.

Marton, F., \& Booth, S. (1997). Learning and awareness. Mahwah N.J.: Lawrence Erlbaum.

Marton, F., \& Pang, M. F. (2006). On some necessary conditions of learning. The Journal of the Learning Sciences, 15(2), 193-220.

Marton, F., \& Pang, M. F. (2013). Meanings are acquired from experiencing differences against a background of sameness, rather than from experiencing sameness against a background of difference: Putting a conjecture to test by embedding it into a pedagogical tool. Frontline Learning Research, 1(1), 24-41.
Marton, F., \& Tsui, A. B. (2004). Classroom discourse and the space of learning. Mahwah: Erlbaum.

Mason, J. (2017). Issues in variation theory and how it could inform pedagogical choices. In R. Huang \& L. Yeping (Eds.), Teaching and learning mathematics through variation. Confusian heritage meets western theories. Boston, MA: Sense.

Nilsson, P. (2014). When teaching makes a difference:developing science teachers' pedagogical content knowledge through learning study. International Journal of Science Education, 36(11), 1794-1814.

Pillay, V. (2013). Enchancing mathematics teachers' mediation of a selected object of learning through participation in learning study: The case of functions in grade 10 (unpublished doctoral thesis). University of Witwatersrand, Johannesburg.

Rittle-Johnson, B., \& Star, J. R. (2009). Compared with what? The effect of different comparsions on conceptual knowledge and procedural flexibility for equation solving. Journal of Educational Psychology, 101(3), 529-544.

Rittle-Johnson, B., Star, J. R., \& Durkin, K. (2009). The importance of prior knowledge when comparing examples: Influence on conceptual and procedural knowledge of equation solving. Journal of Educational Pshychology, 101(4), 836-852.

Rohrer, D., \& Pashler, H. (2010). Recent research on human learning challenges conventional instructional strategies. Educational Researcher, 39(5), 406-412.

Rowland, T. (2008). The purpose, design and use of examples in the teaching of elementary mathematics. Educational Studies in Mathematics, 69(2), 149-163.

Rowland, T., Thwaites, A., \& Huckstep, P. (2003). Novices' choice of examples in the teaching of elementary mathematics. Paper presented at the The Mathematics Education into the 21th Century Project. Proceedings of the international conference The Decidable and the Undecidable in Mathematics Education, Brno, Czech Rebublic.

Runesson, U. (2006). What is it possible to learn? On variation as a necessary condition for learning. Scandinavian Journal of Educational Research, 50(4), 397-410.

Runesson, U., \& Kullberg, A. (2017). Learning to teach with variation. Experiences from learning study in Sweden. In R. Huang $\&$ L. Yeping (Eds.), Teaching and learning mathematics through variations. Boston, MA: Sense.

Ryle, G. (1949/2002). The concept of mind. Chicago: University of Chicago Press.

Schmidt, R. A., \& Bjork, R. A. (1992). New conceptualizations of practice: common principles in three paradigms suggest new concept for training. Psychological Science, 3(4), 201-217.

Schön, D. A. (1983). The reflective practitioner. How professionals think in action. New York: Basic Books.

Schwartz, D. L., \& Bransford, J. D. (1998). A time for telling. Cognition and Instruction, 16(4), 475-522.

Sun, X. (2011). "Variation problems" and their roles in the topic of fraction division in Chinese mathematics textbook examples. Educational Studies in Mathematics, 76(1), 65-85.

Taylor, K., \& Rohrer, D. (2010). The effects of interleaved practice. Applied Cognitive Psychology, 24(6), 837-848.

Vikstrom, A. (2014). What makes the difference? Teachers explore what must be taught and what must be learned in order to understand the particular character of matter. Journal of Science Teacher Education, published online. doi:10.1007/ s10972-014-9397-9.

Watson, A., \& Chick, H. (2011). Qualities of examples in learning and teaching. ZDM, 43(2), 283-294.

Watson, A., \& Mason, J. (2006). Seeing an exercise as a single mathematical object: using variation to structure sense-making. Mathematical Teaching and Learning, 8(2), 91-111. 
Yoshida, M. (1999). Lesson study: A case study of a Japanese approach to improving instruction through school-based teacher development. Illinois: University of Illinois.

Zhang, Y. (2009). Variation for the improvement of teaching and learning project: An English case on teaching personal pronouns of English language. Hong Kong: School Partnership and Field Experience Office, the Hong Kong Institute of Education.

Zodik, I., \& Zaslavsky, O. (2008). Characteristics of teachers' choice of examples in and for mathematics. Educational Studies in Mathematics, 69(2), 165-182. 